\title{
MÉTRICA DE LAS COPLAS DE JORGE MANRIQUE
}

Nota fonológica. A pesar de sus cinco siglos de antigüedad, el lenguaje de las Coplas de Jorge Manrique es claro y sencillo para cualquier lector moderno. Por su propiedad y sobriedad parece que jamás ha de envejecer. Sus pocos y leves arcaísmos pasan casi desapercibidos: parescer, sobir, cativa, estorias, joventud, etc. La lectura a la manera actual de otras palabras como dulçores, plazeres, dexó, mejor, modifica su antigua pronunciación, pero no altera la forma de los versos. Sólo afectan a la métrica los detalles siguientes: La $i$ cuenta como vocal en hiato, con diéresis, en glorïosa, juïcio, Octavïano, Aureliano, Adrïano. En el mismo caso se halla la $e$ de Tëodosio. La sinalefa se cumple regularmente entre vocales inacentuadas, sin más excepciones que "y otros por no tener" (copla 20) y "de sus fijos y hermanos" (79); otras veces la y se suma a la vocal inmediata: "y en las-lides que venció" (58), "por méritos y ancianía" (62). La aspiración de la $h$ impide la agrupación de las vocales en "la cava honda, chapada" (48), "después de tanta hazaña" (66), "y su halago" (67) y en otros casos; la $f$ originaria se mantiene en fazer, fizo, fizieron, fable, falaguero, etc.

Estrofa. Están compuestas las Coplas en sextillas octosílabas, cuyos versos se reparten en dos semiestrofas iguales con terminación quebrada en cada una de ellas y con tres rimas consonantes correlativas, abe:abe. Se ha venido usando esta estrofa en la poesía española desde mediados del siglo xv, a partir de Juan de Mena. Fue ampliamente cultivada por varios poetas durante la segunda mitad de ese siglo. Algunas otras de las muchas clases de estrofas de pie quebrado usadas desde el Arcipreste de Hita fueron quedando abandonadas hasta entrado el siglo xvi. La fama de las Coplas de Manrique ha mantenido hasta hoy el recuerdo, estimación y ejercicio de su conocida sextilla. Aunque con descensos y reacciones de frecuencia, en ninguna época ha dejado de tener cultivadores. Es en realidad la única estrofa que ha sobrevivido entre las numerosas invenciones de la métrica trovadoresca. El nombre con que generalmente se la designa es el de "copla de Jorge Manrique".

En los antiguos cancioneros, estas sextillas aparecen agrupadas en 
parejas. Las ochenta sextillas de que constan las Coplas formaban cuarenta estrofas dobles. La diferencia de rimas entre las dos sextillas de cada pareja dio lugar a que cada una de ellas llegara a considerarse como unidad independiente. Ocurre además que la mayor parte de las sextillas de las Coplas ofrecen individualidad bien definida, no sólo por razón de sus rimas, sino por su propio sentido. En varios casos, sin embargo, entre una sextilla impar y la que le sigue existe un enlace sintáctico y semántico que da a entender que su originaria agrupación en parejas no significaba una práctica meramente formal. Confirma esta misma relación el hecho de que en ningún caso una sextilla par aparezca trabada con la impar siguiente. Sólo con ocasión de las sextillas $65-66$ se advierte que el sentido desborda la pareja y se extiende sobre la inmediata. Ambos modos de representación, sencilla o doble, igualmente compatibles con la métrica y el contexto del poema, se practican en las ediciones modernas. El de estrofas simples, que aquí sirve de base, ofrece la ventaja práctica de facilitar más concretamente la localización de las referencias.

De la sextilla de pie quebrado puede decirse que es la más armoniosa de las estrofas octosílabas. Sobre las proporciones de la redondilla de rimas cruzadas, añade la cadencia de los dos versos cortos que prolongan el efecto de las semiestrofas. Es más breve y flexible que las octavillas del romanticismo; no se somete como ésta a la rígida disciplina de las rimas agudas al final de las dos mitades de la estrofa. Su disposición lírica le ha hecho ser preferida en serenatas y barcarolas. Sus octosílabos se prestan a diversas correspondencias interiores a base de la combinación de sus tipos rítmicos. Dispone, además, de la libertad de hacer el pie quebrado tetrasílabo o pentasílabo. Claro es que el papel de la sextilla, dentro de su claro esquema métrico, es más o menos musical, expresivo y artístico según la acción conjunta de los varios elementos que puede poner en juego. Las observaciones siguientes se refieren a la aplicación de algunos de estos recursos en la métrica de las Coplas.

Octosílabo. En los octosílabos de esta composición intervienen los varios tipos rítmicos que tal metro contiene. Predomina el tipo trocaico, aunque no con la alta proporción que había alcanzado en el período de la gaya ciencia. El tipo dactilico y las variedades mixtas muestran por su parte mayor representación que en los poetas de ese período anteriores a Jorge Manrique. Sus proporciones en las Coplas pueden representarse de este modo:

$\begin{array}{lll}\text { trocaico: } & \text { oo óo óo óo } & 43,0 \% \\ \text { mixto } a: & \text { o óo óoo óo } & 22,2 \\ \text { mixto } b: & \text { o óoo óo óo } & 15,9 \\ \text { dactílico: } & \text { óoo óoo óo } & 16,7 \\ \text { otros: } & & \\ \end{array}$


El compás nivelado y uniforme del trocaico forma el fondo rítmico de las Coplas, pero entre las ochenta sextillas sólo la 69 y la 71 se ajustan con regularidad a este único tipo. Hay, además, como una docena de estrofas en que un solo verso se aparta de la línea trocaica. En muchas otras, en cambio, el número de trocaicos se reduce a uno o dos versos, y pasan de una docena las que excluyen enteramente ese tipo rítmico. El predominio del trocaico había obedecido probablemente a influencia galaico-provenzal. El testimonio de las Coplas revela la señalada inclinación que en el tiempo de Jorge Manrique operaba para restablecer en el campo de la poesía culta el modo de octosílabo polirrítmico usado en todo tiempo por la lírica popular castellana.

Unos pocos versos se apartan de los modelos corrientes. En lectura incolora pueden acomodarse a la forma trocaica, pero se trata precisamente de octosílabos cuya particularidad rítmica parece obedecer al propósito de subrayar su propio papel expresivo. Uno de ellos es "Tito, en liberalidad" (copla 54), en el que el primer tiempo marcado, con apoyo sobre la sílaba inicial, destaca el nombre que se menciona como dechado, al que se une en sinalefa la preposición en, mientras que el tiempo débil recoge las cuatro sílabas siguientes: óo óooo ó. Análoga disposición ofrece “¿Qué fue sino claridad” (44), donde, como es lógico, el refuerzo de la pregunta recae sobre el pronombre inicial. En otros casos el primer tiempo marcado se reduce a la sílaba tercera, a la cual sigue una cláusula dactílica en que se concentra el énfasis del sentido:

$$
\text { oo ó óoo óo }
$$

cuando tú, cruda, te ensañas

No dexó grandes tesoros ni alcançó grandes riquezas $\quad 57$

$\mathrm{Y}$ pues vos, claro varón

que querer ombre bivir

cuando Dios quiere que muera $\quad 7^{6}$

nos dexó harto consuelo 80

No es fácil descubrir el motivo o intención del modo en que las diferentes especies de octosílabo se hallan situadas en cada copla. En la mayor parte de las sextillas intervienen dos o tres de tales modalidades o tipos sin ningún orden apreciable. Pero son también relativamente numerosos los casos en que las indicadas modalidades muestran un determinado orden en que es posible ver cierta correspondencia con el carácter de los respectivos pasajes. Su disposición permite distinguir cuatro formas características: paralela, alterna, inversa y uniforme. 
Disposición paralela. Los dos octosílabos de la primera semiestrofa, pertenecientes al mismo tipo, contrastan con los de la segunda, que a su vez son también iguales entre sí. En la copla 1, los dos primeros son del tipo mixto $a$; el movimiento ascendente de su período rítmico ayuda al apremio de la recomendación: "Recuerde el alma dormida, / abive el seso y despierte". Los segundos, dactílicos, refuerzan la gravedad de la exclamación: "cómo se pasa la vida, / cómo se viene la muerte". En la copla 6, los dos primeros, mixtos $a$, describen con su habitual viveza: "Allí los ríos caudales, / allí los otros medianos"; los segundos, trocaicos, sugieren reflexión serena y comprensiva: "Allegados son iguales / los que viven por sus manos". En la copla 8, los dos primeros, trocaicos, reflejan esa misma serenidad: "Aquel sólo me encomiendo, / aquel sólo invoco yo"; los segundos, mixtos $a$, hacen notar mayor emoción: "que en este mundo biviendo / el mundo no conoció". Lo que a primera vista puede parecer una vaga interpretación afirma sus líneas al repetirse en las coplas $5^{\circ}$, 52 y 70 , que muestran análogas combinaciones paralelas de mixtos $a$ y trocaicos, y en 19, 31, 35 y 69, que repiten la disposición opuesta de trocaicos y mixtos $a$. Con notoria correspondencia, unos y otros aparecen ligados respectivamente en estos pasajes al tono refrenado y a la expresión emocional.

Disposición alterna. Los dos octosílabos de la primera semiestrofa, diferentes entre sí, reaparecen en el mismo orden en la semiestrofa siguiente. La desigualdad de cada pareja se concierta en la unidad de la copla. Es posible que en general la presencia de esta combinación responda meramente al atractivo de su armonía. No se ocultan, sin embargo, sus movimientos expresivos. En la copla 5 , el primer octosílabo es trocaico y el segundo mixto $a$ : "Nuestras vidas son los ríos / que van a dar en la mar"; el cuarto y el quinto repiten esos mismos tipos: "allá van los señoríos / derechos a se acabar". Al enunciado del primer verso, responde con mayor viveza en ambos casos la declaración del segundo. Igual orden se observa entre las mismas variedades indicadas en las coplas 43 y 75 . En la 29, la alternancia se produce entre el primer octosílabo, apremiante, mixto $b$, y el segundo, complementario, trocaico: "Dexemos a los troyanos, / que sus males no los vimos"; idéntica disposición entre el cuarto y quinto: "Dexemos a los romanos, / aunque oímos y leímos". El contraste alternativo resalta en la copla 33 entre el primero, dactilico, y el segundo, trocaico: "¿Qué se fizieron las damas, / sus tocados, sus vestidos?"; el cuarto y quinto se suceden con iguales características: "¿Qué se fizieron las llamas / de los fuegos encendidos?” De manera análoga, el tipo dactilico y el mixto $b$ alternan en la copla 14, y el dactilico y el mixto $a$ en la 77 . Los tres versos mixtos que apoyan con su tensión el repetido adverbio después en las coplas 65 y 66 , realzan su tono por contraste con los trocaicos que les siguen: 


$\begin{array}{cc}\text { MÉtrica de las "Goplas" DE Manrique } \\ \text { Después de puesta la vida } & \text { mixto a } \\ \text { tantas veces por su ley... } & \text { trocaico } \\ \text { Después de tan bien servida } & \text { mixto b } \\ \text { la corona de su rey... } & \text { trocaico } \\ \text { Después de tanta hazaña } & \text { mixto a } \\ \text { a que no puede bastar... } & \text { trocaico }\end{array}$

Disposición inversa. Los dos octosílabos de la primera semiestrofa, diferentes entre sí, se repiten en la segunda en orden opuesto. Aunque en distinta dirección, ambos movimientos se corresponden y completan. En la copla 72 , el primer octosílabo, trocaico, y el segundo, dactílico, revelan tensión ascendente: "Mas los buenos religiosos / gánanlo con oraciones"; el cuarto, dactilico, y el quinto, trocaico, indican tensión descendente: "Los caballeros famosos, / con trabajos y aflicciones". Análogo orden inverso se observa en la copla 23 entre trocaico y mixto $a$ en la primera parte, y mixto $a$ y trocaico en la segunda, e igualmente en la copla 41 entre trocaico y mixto $b$ de un lado y mixto $b$ y trocaico de otro. En algunas ocasiones el movimiento es descendente en la primera semiestrofa y ascendente en la segunda, como se ve en la copla 47 , en que el primer octosílabo es mixto $a$ y el segundo trocaico: "Las huestes innumerables, / los pendones y estandartes", mientras que, por el contrario, el cuarto es trocaico y el quinto mixto $a$ o $b$ : "los castillos impunables, / los muros y baluartes". Al mismo orden descendente-ascendente corresponde la copla 68 , en la que los octosílabos de la primera mitad son un dactilico y un mixto $b$ y los de la segunda un mixto $b$ y un dactilico.

Disposición uniforme. Frente a la múltiple variedad dominante en este aspecto de la métrica de las Coplas, llama la atención la presencia de las sextillas 63 y 71 , ya mencionadas, en las que los octosílabos y sus quebrados son uniformemente trocaicos. Es de notar que tal uniformidad, aunque deba suponerse nacida de simple impulso espontáneo, resulta de perfecto acuerdo con el llano carácter descriptivo y didáctico de una y otra copla. La insistencia del tipo mixto $a$ en los cuatro octosílabos de la copla 10 ahonda la concentrada visión del curso de la vida a que la estrofa se refiere. En los casos en que la uniformidad rítmica es alterada por un determinado verso, no es difícil percibir el motivo de la alteración. El octosílabo inicial de la copla 17 , mixto $a$, atrae el interés respecto a la exposición enumerativa de los tres trocaicos siguientes. El segundo octosílabo de la copla 12, dactilico, rompe con devota emoción el fondo trocaico de la escena religiosa que los versos evocan. Papel semejante desempeña el tercer octosílabo, otro dactílico entre trocaicos, en la copla 21. En la 26, el segundo octosílabo, mixto $b$, subraya la idea de rapidez en contraste con el moderado compás trocaico de los demás versos. 
La reflexiva copla 9 interrumpe su serenidad trocaica con la aleccionadora advertencia del tercer octosílabo, mixto $b$. En la copla $3^{8}$, el cuarto octosílabo, también mixto $b$, resume y realza el sentido, después de la nivelada línea trocaica de los versos anteriores.

Dacrílico. El tipo dactilico, no sólo con preferencia al trocaico sino asimismo con relación a los mixtos, aparece repetidamente en las Coplas en los momentos de expresión más firme, intensa y grave. Es rasgo notable en Jorge Manrique el haber desarrollado esta variedad de octosílabo, de tan definido y eficaz valor expresivo. Aunque por su frecuencia no ocupa sino uno de los últimos lugares, su papel se destaca con especial relieve, aplicado sobre todo a exclamaciones, invocaciones, preguntas, mandatos y afirmaciones enfáticas. Algunos ejemplos han sido aludidos en las citas anteriores. No será necesario añadir muchos más:

$$
\text { óoo óoo óo }
$$

Qué diligencia tan biva

Todo se torna graveza 14

Unos, por poco valor

18

Tantos marqueses y condes

20

Todo lo pasas de claro

45

Muestre su esfuerço famoso

Aumenta la intervención del tipo dactílico en la parte final de la composición, cuando el poeta se refiere más concretamente a la muerte de su padre. Se observa que esta variedad de octosílabo tiende a ejercer su peso sobre todo en la segunda semiestrofa. Después de la serie alterna de mixtos y trocaicos que refiere los méritos de don Rodrigo, dos dactilicos finales, en la copla 66, con grave y tensa emoción, marcan sus últimos momentos:

En la su villa de Ocaña

vino la muerte a llamar a su puerta.

La invocación en que el caballero encomienda su alma al Señor termina con una estrofa $(78)$ en que tres de sus cuatro octosílabos son dactilicos y uno mixto $b$ :

Tú, que tan grandes tormentos sofriste sin resistencia en tu persona, no por mis merescimientos, mas por tu sola clemencia me perdona.

Pie quebrado. El pie quebrado es regularmente tetrasílabo en 60 de las 80 sextillas. Su natural ritmo trocaico se suma al de los octo- 
sílabos de este mismo carácter que, como se ha visto, predominan en el poema. En las estrofas restantes, los dos quebrados de cada copla o uno de ellos consta de cinco sílabas. Jorge Manrique observó en este punto la regla practicada en su tiempo de no aplicar el quebrado pentasílabo sino en condiciones de compensación o sinalefa respecto al octosílabo precedente. La compensación ocurre tras octosílabo agudo: "pues que todo ha de passar / por tal manera" (4). La sinalefa requiere vocal final en el octosílabo e inicial en el pentasílabo: "se sume su grand alteza / en esta vida" (17).

La indicada regla era meramente potestativa. El autor no la infringió ni la aplicó de manera sistemática. En ocho coplas $(5,18,31$, $36,53,54,61,70$ ), después de los octosílabos segundo y cuarto, agudos, siguen pentasílabos de compensación. En otras ocho $(8,9,17$, $39,56,64,65,66)$, después de octosílabos igualmente agudos siguen tetrasílabos sin compensación. En cuatro más $(4,11,55,77)$, después de octosílabos de esa misma especie, un quebrado es tetrasílabo y otro pentasílabo. El pentasílabo con sinalefa obedece a condiciones más estrictas. En ocho estrofas aparece exclusivamente en el segundo pie quebrado $(13,19,22,25,40,49,67,69)$; sólo en la estrofa 78 figura como quebrado primero. En las coplas 14 y 80 , los primeros quebrados, en concurrencia de vocales con los octosílabos precedentes, no son pentasílabos con sinalefa sino tetrasílabos con hiato. La circunstancia de lugar se advierte aún más claramente en la copla 4o, cuyo primer quebrado es tetrasílabo con hiato, y el segundo, pentasílabo con sinalefa.

Tanto la compensación como la sinalefa, con el alargamiento que el pentasílabo representa, prestan cierto relieve al pie quebrado. La compensación procede con orden simétrico, guardando el equilibrio de la estrofa; la sinalefa, como con frecuencia el octosílabo dactilico, apoya la segunda mitad. Por razón de su simetría debe adscribirse al primer grupo la copla 61, cuyos quebrados pentasílabos tras octosílabos agudos se hallan igualmente en condiciones de compensación y de posible sinalefa: "que con su braço pintó / en joventud", "agora las renovó / en senectud". Excepción única es la copla 76 , en la que el hiato entre el quebrado final, tetrasílabo, y el octosílabo anterior, sirve eficazmente al efecto particular del sentido: "que querer ombre bivir / cuando Dios quiere que muera, / es locura".

Descartada por compensación o sinalefa la primera sílaba del quebrado pentasílabo, la función de éste adquiere el mismo valor que la del predominante tetrasílabo, con lo cual se nivela la aparente desigualdad métrica. Favorece el ritmo trocaico el hecho de que la segunda sílaba del pentasílabo sea acentuada: "por tal manera" (4), "en este trago" (67). Cuando la primera sílaba del pentasílabo lleva acento, aunque teóricamente empalme con el octosílabo anterior, sin duda mantiene su carácter dactílico: "que es el morir" (6), "¿qué se 
fizieron?" (31). Recuérdese que en la lengua hablada los grupos pentasílabos con único acento en la cuarta sílaba se inclinan ordinariamente a la forma dactilica. Es posible asociar a este tipo quebrados como "angelical" (13), "con alegría" (54), "que prometía" (54), "ni verdadera" (70), "perescedera" (70). Por lo demás, se ha probado experimentalmente que el enlace entre el octosílabo y el pie quebrado se acomoda al tiempo regular del período rítmico con sinalefa o hiato y con compensación o sin ella.

Rrma. El principal elemento de variedad en la estrofa es la rima. En las Coplas, la rima es consonante y predominantemente llana. No más del $25 \%$ del total de los versos, octosílabos y quebrados, presentan rimas agudas. No hay ningún verso esdrújulo. Las rimas llanas concuerdan con el sereno fondo del poema. Además, por su calidad fonológica corresponden en su gran mayoría a las combinaciones vocálicas más sonoras y llenas. Sobre este fondo, acusan su realce las rimas agudas, haciéndose notar especialmente, con su reforzado apoyo, en el grave tono filosófico de la introducción y en la honda y noble emoción de las estrofas finales.

Recaen con preferencia las rimas agudas sobre los primeros versos de las semiestrofas. Del $25 \%$ indicado, el $11 \%$ de tales rimas se encuentra en esa posición; las restantes se reparten en porciones iguales de $7 \%$ entre el segundo octosílabo y el pie quebrado. Refleja este orden cierta tensión descendente dentro de cada semiestrofa desde el relieve del primer verso hasta la reducción del pie quebrado. Sobresalen en las rimas agudas, como en las llanas, las vocales más abiertas y claras. Tienen representación mínima la $i$ y la $u$.

La acción directa de la rima se funda en la repetición de su resonancia, ya por identidad, como en la rima consonante, ya por semejanza, como en la asonante. Ejerce además la rima una acción indirecta que consiste en su diferenciación o contraste respecto a las demás rimas que la acompañan. En el contraste de unas rimas con otras, se dan también grados de diferenciación. Son plenamente contrastantes las rimas que difieren entre sí por sus vocales acentuadas y por los sonidos siguientes: -amas, -idos, -ores (copla 33). El contraste es sólo parcial cuando las rimas difieren por las vocales acentuadas, pero coinciden en los demás sonidos: -emos, -imos, -amos (10). Otro grado de contraste atenuado ocurre cuando los sonidos finales difieren mientras las vocales acentuadas coinciden: -á, -amos, -ales (24). Los contrastes atenuados son modos de resonancia incompleta, como la misma rima asonante, aun cuando la práctica ordinaria no los reconozca ni sancione. Cuentan con precedentes en la métrica histórica. Los varios modos indicados de diferenciación alternan en las Coplas entre las rimas de cada estrofa, pero el contraste pleno, que es el que hace distinguir con más claridad unos versos de otros, es el que ocupa el primer lugar en el conjunto del poema. Al tercer grado, 
de vocales acentuadas coincidentes y sonidos finales discrepantes, corresponden las coplas 11, 24, 71 y 72. Las cuatro se asemejan en su insistente y austero tono moral. Del grado segundo sólo se registra la citada estrofa 10. Como una docena de casos muestran formas oscilantes e intermedias, en general más próximas al contraste pleno que a los atenuados.

Armonía vocálica. Dentro del verso las vocales adoptan múltiples combinaciones diferentes. Los efectos más perceptibles son los que resultan de la disposición de las vocales destacadas por los apoyos rítmicos. Se hallan en este caso en el octosílabo, además de la vocal que recibe el acento final en la sílaba séptima, la que sirve de asiento al primer tiempo marcado en una de las tres primeras sílabas del verso y la que corresponde al tiempo débil en una de las sílabas intermedias. En la mayoría de los 240 octosílabos de las Coplas, las vocales que ocupan esos tres lugares son distintas entre sí. Su eficacia diferenciadora se suma a la de las rimas contrastantes. Ciertas combinaciones, sin embargo, de disposición equilibrada y armónica, se hacen notar por su propio carácter y algunas de ellas, además, por su relativa frecuencia, la cual no parece que pueda obedecer a otra causa sino al atractivo eufónico que esas mismas combinaciones encierran.

En nueve versos a lo largo de las Coplas se repite la serie vocálica a-e-a: "Sus grandes fechos y claros" (50), "ocupadas de tiranos" (63), "tanta sangre derramastes" (73), etc. En otras tantas ocasiones aparece e-a-e: "Cuán presto se va el plazer" (2), "cuando viene la vejez" (17), "Qué seso para discretos" (52), etc. Se encuentran cuatro casos de e-o-e: "pues si vemos lo presente" (3), "d $e$ los famosos poetas" (7), etc. Otros cuatro versos presentan $o-e-o$, dos en la misma estrofa: "con otras nuevas victorias / agora las renovo" (61). Varias otras series ofrecen ejemplos particulares, $a-i-a$ : "que a los grandes $y$ medianos" (47); a-o-a: la cava honda, chapada" (48); o-a-o: "No dexó grandes tesoros" (57); i-a-i: "Las vaxillas tan febridas" (37); $i$-o-i: "con of $i$ cios no debidos" (20); ie-au-ie: "que le dieron aun más tierra" (6o).

Junto a la variable disposición vocálica de la generalidad de los versos y a la ordenada simetría de las series indicadas, llaman la atención otros casos que, opuestamente, se caracterizan por la uniformidad de sus vocales rítmicas. La resonancia de la $a$, extendida a veces a sílabas fuertes y débiles, llena cinco versos como los siguientes: "que van a dar a la mar" (5), "en los más altos estados" (16), "no se os faga tan amarga" (69). Con análoga insistencia se repite en otras ocasiones la palatal $e$ : "si fuesse en nuestro poder" (13), "corremos a rienda suelta" (26), "no curemos de saber" (30). Otras veces domina la nota oscura de la 0 : "aquel solo invoco yo" (8), "¿qué son sino corredores?" (25), "como los pobres pastores" (28). El 
dominio de la $a$ abarca dos versos consecutivos en la copla 59: "quedando desamparado / con hermanos y criados".

Resumen. Bajo su sencilla apariencia, la Coplas encierran una compleja y refinada estructura métrica. No escogió Jorge Manrique para su elegía la solemne octava de arte mayor ni la pulida copla real. En sus manos, la ligera sextilla de pie quebrado, sin perder su acento lírico, adquirió madurez y gravedad. El octosílabo aparece en esta poesía como un dúctil instrumento utilizado en toda la variedad de sus recursos, con plenitud no alcanzada en obras anteriores. La forma trocaica que sirve de base deja amplio margen a las demás variedades. Gran número de versos, en situación de contraste u organizados en posiciones diversas, puntúan, avivan o refrenan la expresión en determinados pasajes, por virtud de sus efectos rítmicos. Un esmerado sentido de coordinación guía la cadencia del pie quebrado en las oscilaciones de su medida y en su relación con cada semiestrofa. La calidad y disposición de las rimas trasluce perceptibles afinidades con el orden de las estrofas y de las partes del poema. Versos con interior armonía vocálica intercalan en el curso de la composición su melodiosa sonoridad.

Los hechos señalados se manifiestan de manera demasiado repetida y consistente para que puedan atribuirse a mera y casual coincidencia. A su trabado conjunto deben sin duda las Coplas su particular equilibrio y armonía, aunque los pormenores de este análisis no logren descubrir todo el secreto de su magia. En consonancia con su austera doctrina y con su ponderada emoción, el tono del poema es acompasado y sereno. Sus variados recursos métricos se articulan sin esfuerzo de estudiado y laborioso artificio. No hay que pensar que Jorge Manrique se propusiera deliberadamente poner en juego tan minuciosos y delicados detalles; pero, por otra parte, tampoco se puede decir que se trate de una técnica común y corriente en composiciones de esta ni de ninguna otra especie. Aunque el verso. octosílabo había ya pasado por largo e intenso cultivo y la misma sextilla había sido ampliamente practicada, sería difícil señalar otro ejemplo en que estas formas métricas hubieran sido manejadas con la depurada maestría que las Coplas demuestran. Dio ejemplo el autor de agudo sentido intuitivo para penetrar el mecanismo de tales instrumentos y para hacer aplicación de sus delicados registros.

Todo el poema aparece concebido como una gran estrofa dividida en dos partes de equivalente extensión. La primera mitad, como meditación filosófica, sirve de marco a la segunda, propiamente elegiaca. Desde este punto hasta el plano dominante de los versos trocaicos, los más visibles elementos de la composición se funden con el orden métrico en la misma alternativa disposición dual. La lengua 
combina y contrapesa formas antiguas y modernas: fermosa-hazaña, vos-os, recordar-despertar, esforçado-valiente. Sobre términos paralelos y contrastantes se desenvuelve el razonamiento: vida-muerte (copla 1), placer-dolor (2), presente-pasado (3), durar-pasar (4), cielosuelo (12), corporal-angelical (13), juventud-senectud (18), temporales-eternales (24), emperadores-pastores (28). La copla 10 condensa la correlación rítmica: partir-nacer, andar-vivir, llegar-morir.

Una construcción tan entretejida de correspondencias rítmicas y armonías interiores no sólo no es corriente en otras obras poéticas, sino que el mismo Jorge Manrique tampoco la ejecutó con tal refinamiento en poemas suyos de igual tipo de estrofa, como por ejemplo el titulado Castillo de amor. Ni las variedades rítmicas del verso ni la disposición de las rimas alcanzan en esta poesía el estrecho y concertado orden que en las Coplas presentan. En la composición de las Coplas, movida por la emoción de un íntimo suceso familiar, debieron concurrir circunstancias especiales de sensibilidad e inspiración, merced a las cuales, el poeta, más que en otras ocasiones, acertó a encontrar en las palabras y en los versos su pleno sentido y su escondida virtud musical. Por otra parte, en su sosegado compás y en su moderada entonación, las estrofas de este poema muestran esencial concordancia con los rasgos más significativos del acento castellano. Sobre este fondo, las Coplas mantienen su no envejecido estilo y su clara imagen sonora. Su perpetua modernidad tiene sus raíces en el subsuelo del idioma. 